Alodoxia afectiva. Una política de las emociones en el neoliberalismoPablo

Daniel, Sánchez Ceci

Question/Cuestión, Nro.70, Vol.3, diciembre 2021

ISSN: 1669-6581

URL de la Revista: https://perio.unlp.edu.ar/ojs/index.php/question/

IICom -FPyCS -UNLP

DOI: https//doi.org/10.24215/16696581e615

\title{
Alodoxia afectiva. Una política de las emociones en el neoliberalismo
}

Affective allodoxia. A politics of emotions in the neoliberalism

Pablo Daniel Sánchez Ceci

Instituto de Estudios en Comunicación, Expresión y Tecnología; Universidad Nacional de Córdoba/

Consejo Nacional de Investigaciones Científicas y Técnicas

Argentina

sanchezcecipablodaniel@gmail.com

https://orcid.org/0000-0001-7440-1307

\section{Resumen}

El tema de este trabajo es la producción de políticas culturales de las emociones en el neoliberalismo reciente, es decir el vínculo entre afectos y políticas expresado en materialidades discursivas. Nuestro objetivo es presentar un primer análisis que articula categorías del análisis del discurso, el giro afectivo y la filosofía política posfundamento, a partir de una serie de discursos como una muestra parcial de cómo se configuran algunas emociones como legítimas y otras no. 
El ensayo que sigue está dividido en cuatro secciones. En la primera presentaremos un corpus de discursos del ex-presidente Mauricio Macri en distintos momentos de su trayectoria política para identificar la configuración de la dimensión afectiva. En el segundo apartado recuperaremos el análisis del discurso de Macri en términos del neoliberalismo como lengua afectiva y como promesa/amenaza a partir de los desarrollos de Dahbar y Levstein (2020). En el tercer apartado, recuperaremos las consideraciones de Martínez (2020) sobre «la autonomía como ideal moral y estigmatización de la demanda» como organizadoras de una cierta economía afectiva resultante de los vínculos entre precarización y neoliberalismo. Finalmente, proponemos la noción de alodoxia afectiva a partir de desarrollar la interpretación que Ahmed (2019) realiza de «La distinción» de Bourdieu.

Palabras clave: Giro afectivo; Cambiemos; Discurso; Neoliberalismo

\section{Abstract}

The theme of this work is the production of cultural politics of emotions in recent neoliberalism, that is, the link between affects and politics expressed in discursive materialities. Our objective is to present a first analysis that articulates categories of discourse analysis, affective turn, and post-foundational political philosophy, based on a series of discourses as a partial sample of how some emotions are configured as legitimate and others not.

The essay that follows is divided into four sections. In the first, we will present a corpus of speeches by former president Mauricio Macri at different times in his political career to identify the configuration of the affective dimension. In the second section we will recover the analysis of Macri's discourse in terms of neoliberalism as an affective language and as a promise / threat based on the developments of Dahbar and Levstein (2020). In the third section, we will recover Martínez's (2020) considerations on "autonomy as a moral ideal and stigmatization of demand" as organizers of a certain affective economy resulting from the links between precariousness and neoliberalism. Finally, we propose the notion of affective allodoxy from developing Ahmed's (2019) interpretation of Bourdieu's «The distinction».

Keywords: Affective turn; Cambiemos, Discourse; Neoliberalism

\footnotetext{
IICom (Instituto de Investigaciones en Comunicación)

Facultad de Periodismo y Comunicación Social Universidad Nacional de La Plata
} 


\section{Introducción}

El tema de este trabajo es la producción de políticas culturales de las emociones en el neoliberalismo reciente, es decir el vínculo entre afectos y políticas expresado en materialidades discursivas. Nuestro objetivo es presentar un primer análisis que articula categorías del análisis del discurso, el giro afectivo y la filosofía política posfundamento, a partir de una serie de discursos que no pretende ser archivo exhaustivo, sino una muestra parcial de cómo se configuran algunas emociones como legítimas y otras no. Partimos de conceptualizar el funcionamiento del neoliberalismo en tanto hegemonía cultural y técnica de gobierno productora de subjetividades que articula una economía política orientada a la precarización de las distintas formas de vidas con una forclusión de la desobediencia, las prácticas de libertad, el duelo público y las figuras de solidaridad comunitarias. Por otra parte, cuando hablamos de emociones o afectos partimos de una hermenéutica extra-moral que disuelve la oposiciones binarias «razón/emoción, interior/exterior, mente/cuerpo, acción/pasión» (Macón en Berlant, 2020), bueno/malo; si no como contingentes, precarias, susceptibles de adoptar figuraciones diversas a partir de la formación discursiva de acuerdo a sus regularidades, su lenguaje específico y sus marcos de inteligibilidad.

El ensayo que sigue está dividido en cuatro secciones. En la primera presentaremos un corpus de discursos del ex-presidente Mauricio Macri en distintos momentos de su trayectoria política para identificar la configuración de la dimensión afectiva en la caracterizaremos la construcción negativa de ciertas emociones como "el odio, la ira y el resentimiento" que se manifiestan en personalidades políticas adversativas como Cristina Fernández de Kirchner y Estela de Carlotto, mientras que por otro lado puede observarse la elaboración de un ethos discursivo vinculado al "optimismo inclaudicable» que analizaremos en vinculación con las categorías de «optimismo cruel» de Berlant y «imperativo de la felicidad» de Ahmed. En el segundo apartado recuperaremos el análisis del discurso de Macri en términos del neoliberalismo como lengua afectiva y como promesa/amenaza a partir de los desarrollos de Dahbar y Levstein, a los fines de argumentar que la política cultural de las emociones de la hegemonía neoliberal funciona a partir de una subjetivación en el que los afectos producen una cadena equivalencial entre «riqueza», «impunidad» y «despojo afectivo». En el tercer apartado, recuperaremos las consideraciones de Martínez sobre «la autonomía como ideal moral y estigmatización de la

\footnotetext{
IICom (Instituto de Investigaciones en Comunicación) 
demanda» como organizadoras de una cierta economía afectiva resultante de los vínculos entre precarización y neoliberalismo. Finalmente, proponemos la noción de alodoxia afectiva a partir de desarrollar la interpretación que Ahmed realiza de «La distinción» de Bourdieu, para articular los tres argumentos anteriores y presentar como consideración última de este trabajo que las políticas culturales de las emociones en el neoliberalismo son reguladas por un mecanismo que establece las jerarquías y valores de las emociones en la vida social, en las que se obturan los flujos del resentimiento en términos de lucha de clase o conflictividad social y política, se valora positivamente el «despojo afectivo» en tanto experiencia emocional individual que permanece aislada de las demandas sociales que son configuradas a partir de la estigmatización.

\section{Resentimiento como enfermedad y el optimismo inclaudicable}

El pasado 25 de marzo en una entrevista en Radio Mitre con el periodista Jorge Lanata, el expresidente Mauricio Macri de Juntos por el cambio, comparó la experiencia del secuestro del que fue víctima a comienzos de la década del noventa, con el sufrimiento de Estela de Carlotto, presidenta de la asociación Abuelas de Plaza de Mayo, cuya hija Laura Estela Carlotto, fue secuestrada y desaparecida en Buenos Aires, embarazada, a fines de 1977 en la última dictadura cívico-eclesiástica-militar argentina. Su nieto fue apropiado y su identidad cambiada, después de una búsqueda de casi 40 años, pudo ser identificado como otros nietos recuperados.

La intervención de Macri, es particularmente llamativa en torno al rol de las emociones en su discurso y cómo estas se vinculan al «saber» y «poder»:

«Me da mucha pena que no pueda salir del rencor y del odio... Yo supe perdonar. Supe decir que mi vida no va a estar marcada por el resentimiento y el odio a lo que me pasó. Ese fue mi quiebre mental. Ese episodio, que me llevó a ver la muerte de tan cerca, me llevó a decir que tenía que hacer algo distinto en mi vida. Ella no ha podido.» (25 de Marzo de 2021).

En primer lugar, es evidente que las llamadas «emociones negativas» o «pasiones tristes» como el odio, el rencor y el resentimiento son presentadas como nocivas, degradantes para quien las experimenta, como resultado de una incapacidad, impericia o incluso cierta ignorancia resultado de un 
no-poder y no-saber gestionar las emociones y dar el perdón. Este pequeño fragmento discursivo sostiene una política afectiva: hay ciertas emociones que hay que evitar, con saber y poder. Evidencia las huellas de una norma, un dictum, una forma legítima de sentir, una grilla de inteligibilidad de los afectos reconocibles como socialmente válidos en la vida política y la configuración de lo común.

Este fenómeno no es nuevo. Anteriormente, el 29 de julio del año 2018, mientras era presidente, en su cuenta de Facebook Macri publicó una especie de carta abierta titulada: «Contra los discursos de odio». El posteo empieza por una definición clásica y común del concepto «discurso de odio", tal y como se lo suele encontrar en el debate jurídico y diplomático contemporáneo, para después seguir una serie de argumentos sobre los motivos para condenar este tipo de enunciaciones:

«Estoy convencido de que la única manera de alejarnos de los peligros de esos discursos es entenderlos como una enfermedad social y aislarlos hasta que el combustible de su furia se agote... Por eso, no soplemos el fuego de los discursos de odio con argumentaciones y mucho menos con ira. Pero tampoco les tengamos miedo.» (Macri, 29 de Julio de 2018)

En este texto podemos observar más profundamente la complejidad del dispositivo de gestión emocional y las gramáticas afectivas del ex-presidente, que consideramos una expresión particular de la política cultural de las emociones en el neoliberalismo en tanto hegemonía discursiva. El odio es presentado como una "enfermedad social», metáfora que podemos pensar remite a ciertos discursos naturalistas, positivistas o también del darwinismo social, pero también puede ser interesante pensarla como una expresión que define algo sobre el comportamiento que se espera del cuerpo y del lazo social o lo social en sí. Sabemos que las subjetividades neoliberales están profundamente asociadas al individualismo, al mérito personal, al autogobierno de sí y ciertas tecnologías del yo; acá vemos que más allá de cierta idea que considera al neoliberalismo como la represión de lo social en general como un todo, tiene una noción particular de sociedad. Para el neoliberalismo una sociedad sana, es aquella que no tiene odio. Es decir aquella que forcluye la conflictividad social, el agonismo política, la diferencia y la disputa sobre el sentido de lo que puede afectar un cuerpo.

Por otra parte, resulta peculiar que esta política afectiva no recurra a la argumentación, se recomienda no soplar el fuego, no utilizar la retórica. Desaconsejar el debate público y el discurso puede 
sonar particularmente nocivo para teorías liberales, republicanas o asociadas a la socialdemocracia como las vinculadas a Rawls o Habermas. El abandono de la argumentación y la comunicación como estrategia de combate a los discursos de odio, puede no ser liberal en el sentido habermasiano del término, pero si es neoliberal.

De vuelta al presente, en un adelanto disponible en el portal web del diario Infobae a su libro «Primer tiempo», el ex-presidente explica en primera persona (es decir a nivel individual, personal y biográfico) su relación con las emociones como encargado del poder ejecutivo nacional el día del traspaso de mando en la ceremonia de diciembre de 2019:

Como siempre, yo estaba despojado de cualquier emoción de bronca, resentimiento $u$ odio. No la tuve nunca. No sirve, enferma. Al contrario, estaba muy contento por haber contribuido a darle al país la continuidad democrática que nos había faltado durante tanto tiempo. Soy un optimista inclaudicable... Con esos sentimientos a cuestas y una vez cumplido mi rol en la ceremonia de traspaso... Cuando uno no escucha el odio de los demás se libera del dolor, del aspecto humano del dolor que pone en cuestión el amor propio, lo que genera la bronca que no produce nada positivo... Creo que si hay algo que me ha permitido mantenerme sano a lo largo de toda esta experiencia política y de gobierno es haber logrado no odiar a nadie. Ese ha sido mi secreto fundamental. El odio no tiene ningún efecto sobre los otros, lo tiene sobre uno mismo. Y ese efecto es enormemente corrosivo. Tanto que puede terminar matándote. Aquel a quien se odia termina apropiándose de uno hasta dominarlo por completo. La ex presidenta no está bien. No sé si alguna vez lo estuvo. Ya durante sus mandatos notaba un padecimiento interno muy grande. Tiene una verdad de sufrimiento muy dura, una serie de cosas no resueltas desde muy atrás que sólo ella debe saberlas (Lejtman, 14 de Marzo de 2021).

En esta cita en extenso de fragmentos en los que el ex-presidente narra su perspectiva de la ceremonia democrática es evidente el peso central de la dimensión afectiva del relato. En términos de Angenot, el dominante de pathos (2010) es un componente de la hegemonía discursiva en el que se evidencian los efectos de esos enunciados en cómo ciertos temperamentos y estados de ánimos se hacen presente en una época o acontecimiento. En el discurso de Macri, el acontecimiento del fin de su mandato y la entrega de la investidura presidencial al partido de su oposición política, es presentado patéticamente, en el sentido de que lo desbordan las emociones y la reflexión sobre estas tanto en 
como las experimenta él mismo y su adversaria política la ex-presidente e inminente vicepresidenta, Cristina Fernández de Kirchner. Así, podemos decir es notable como la configuración de su posición como enunciador legítimo y su ethos discursivo se caracteriza por una especie de ataraxia propia del estoicismo o una versión new age vulgarizante de la filosofías de cínicos, estoicos y epicúreos; un nirvana afectivo donde no lo dominan las emociones orientadas a sus enemigos. Esta posición de enunciación es inversa a la que destina a la construcción de su otro negativo, su enemigo político y exterior constitutivo: el desborde afectivo particularmente caracterizado por el resentimiento y el malestar de la enfermedad que estas emociones generan. Propone un clivaje: salud contra enfermedad, despojo contra odio. No es menor el peso del significante resentimiento, que parece un huella de ciertas condiciones de producción discursiva; específicamente: una herencia del dispositivo de enunciación anti-populista y anti-peronista del siglo XX que presentaba a Eva Perón como una resentida. Una emoción negativa que define y ontologiza ese rasgo de origen de la maldad del opositor. Otra vez, nada notablemente nuevo, más bien una persistencia de lenguajes políticos y afectivos previos que se reactualizan en identidades políticas que se construyen sobre las ruinas y glorias del pasado reciente. Por fuera del valor que el resentimiento tiene en la cultura política y afectiva argentina, resulta relevante en este punto comentar brevemente la apuesta del crítico cultural y teórico Mark Fisher (2018) por rehabilitar el resentimiento como una fuente de fuerza política anticapitalista, contra las fantasías de pacificación y control social en los escenarios pospoliticos donde se han demonizado profundamente el conflicto y la lucha de clases. A partir de una lectura de Nietzsche, Fisher propone apropiarse de un tipo de resentimiento particular, que «indujera al esclavo a levantarse y superar al amo» (p. 274). A partir de su experiencia en un sindicato de docentes en el Reino Unido, el autor llega a la conclusión de que:

El resentimiento es un afecto mucho más marxista que los celos o la envidia. La diferencia entre resentir la clase dominante y envidiarla, es que los celos implican un deseo por volverse la clase dominante, mientras que el resentimiento sugiere una furia hacia su posesión de recursos y privilegio. Un resentimiento que llevara solo a la inacción quejosa es ciertamente la definición misma de una pasión inútil. Pero el resentimiento no tiene por qué terminar en impotencia... El resentimiento al privilegio y a la injusticia es en muchos casos el primer paso hacia la confrontación de los sentimientos de inferioridad introyectados y dados por sentado (Fisher, 2018, p. 274). 
La cita extensa, da cuenta de que el resentimiento como «motor libidinal» funciona como un respuesta radical al mandato a la positividad y pasividad de la cultura contemporánea y la ideología neoliberal, pero cambien como un mecanismo de respuesta al profundo malestar psíquico, económico y sanitario que han generado las políticas de austeridad en Europa y en el resto del mundo. Ante la epidemia de estrés, ansiedad, y depresión como resultado de la inmensa presión que generan los mandatos de productividad tanto en el tiempo de trabajo como en el supuesto "tiempo de ocio», Fisher propone una política del resentimiento. No es de extrañar que los proyectos neoliberales como el de Macri o anti-populistas del primer anti-peronismo tengan como técnica de gobierno la gestión del flujo del resentimiento de las clases subalternas. Sin embargo, siempre es necesario recordar que para Fisher como otras perspectivas como la del giro afectivo, ninguna emoción, en este caso el resentimiento, es necesariamente negativa o positiva, ya que son contingentes históricamente susceptibles de adoptar distintas articulaciones. Nuestra intención es caracterizar aquí al resentimiento como un "tabú» (Angenot, 2010) del discurso neoliberal y de sus políticas culturales de las emociones, en tanto que se la considera una enfermedad que pone en peligro la vida social que se pretende inmovil.

Por otra parte, el ex-presidente se define así mismo a partir de una figura llamativa, como un «optimista inclaudicable». Como venimos argumentando las emociones en el discurso neoliberal están asociadas a un estado del cuerpo (la salud y la enfermedad), a un estado del lazo social, pero también es llamativo cierta configuración de temporalidades a partir de los afectos. Hay un vínculo íntimo entre emoción y tiempo. En el posteo de Facebook era evidente una especie de esperanza, cierto componente programático y construcción de tiempo futuro deseable en el cual se superan los discursos de odio. En la entrevista en Radio Mitre, opera un negacionismo por comparación al igualar la violencia institucional histórica infinita del genocidio y el autoritarismo con la violencia de su vida privada; diluyendo así el rol de las políticas de memoria del pasado reciente en Argentina. Su optimismo inclaudicable, se presenta como una promesa, como una característica esencial de lo que es, algo infinito e interminable. Recuerda al «optimismo cruel» de Lauren Berlant (2020) y a la felicidad como promesa de Sara Ahmed (2019).

Berlant piensa el concepto «optimismo cruel» para referirse a una relación de apego particular en la que ciertas ideas de un después que posterga los cuestionamientos sobre la crueldad del presente 
en virtud de la orientación a objetos problemáticos que configurarían lo que se percibe como una buena vida. Esta noción se vuelve una herramienta analítica sumamente potente para la lectura de imaginarios como el sueño americano o sus versiones recientes en el neoliberalismo tardío de emprendedorismo y meritocracia. La crueldad a la que se refiere Berlant se manifiesta en lo problemático de los objetos que son fútiles para la buena vida deseada. El optimismo, por otra parte, se refiere a la orientación venturosa de un futuro. Para esta autora, todo optimismo es un poco cruel, cada apego afectivo a objetos fútiles se comparte de manera particular y diversa. Esta categoría nos permite caracterizar al ethos discursivo (como se construye como sujeto, a que virtudes, valores, razones lo legitiman como un interlocutor válido y legítimo del campo social y específicamente político en el cual se presenta estratégicamente mediante apuestas y efectos de discurso), del dispositivo de enunciación del expresidente como propio de las narrativas del optimismo cruel, es decir se presente como una persona orientada la búsqueda a pesar del fracaso o lo fútil, por eso es «inclaudicable». Para Berlant es claro que las narrativas de las mitologías del neoliberalismo es necesario una dosis de optimismo cruel para caracterizar a sus personajes, es de alguna manera la (dis)posición afectiva que permite que la crueldad y la impredecibilidad de la precarización propia de la desregulación financiera y el capitalismo salvaje sea soportable.

Por otra parte, consideramos que el sintagma «optimista inclaudicable» se presenta como una promesa de felicidad y de una buena vida, para la teórica del giro afectivo, este tipo de estructura afectiva «constituye la fórmula básica de toda religión y moral» (Ahmed, 2019, p. 73). Podríamos pensarla como una manifestación contemporánea del capitalismo como religión que criticó Benjamin y los lazos entre ética protestante y el espíritu de la economía capitalista moderna que caracterizó Weber. Como la cultura terapéutica que es el neoliberalismo propone un diagnóstico (enfermedad social), una sintomatología (el populismo), un virus (el odio, el resentimiento, la ira) y una cura: el optimismo, esa orientación a la felicidad "desideologizada», «pospolítica», "deshistorizada», "despojada afectivamente». Como tecnología afectiva de gobierno, el neoliberalismo tiene una relación fetichizante con la felicidad. Recordemos que una de los primeros slogans de campaña del presidente Macri en 2015 fue la promesa de una «revolución de la alegría», también en un acto en la provincia de Córdoba (bastión de Cambiemos y Juntos por el cambio después a nivel nacional y del peronismo no-kirchnerista 
a nivel provincial) el entonces candidato prometió: «un Cordobazo del crecimiento, un Cordobazo del desarrollo de Argentina»(Molina, 22 de Octubre de 2015).

La felicidad en tanto promesa e imperativo cultural que compulsivamente sigue la orientación el mandato a expresar esta figura afectiva es lo que define la personalidad y el ethos discursivo del expresidente a la que vez que es de lo que carecen sus opositores, como dice Ahmed «rehusarse a la promesa de la felicidad es rehusarse a la demanda de mostrar signos de felicidad» $(2019$, p. 151). Así la enfermedad toma el cuerpo del enemigo, aquel que está cargado de emociones negativas y solo expresa resentimiento, tiene ese "padecimiento» que en los fragmentos de "Primer tiempo» se le adjudican a Fernández de Kirchner. Aquello que perturba la promesa de la felicidad, es lo que promueve la grieta, un atentado contra «la unión de los argentinos» y las formas institucionales de la moderna política republicana y democrática. Una construcción afectiva particular, el «optimismo inclaudicable» (pariente del optimismo cruel y la promesa de la felicidad) es la condición de posibilidad para la vida política y en última instancia de la vida misma, ya que el resentimiento «puede terminar matándote».

Esto último nos parece relevante en función de entender la complejidad del vínculo entre política cultural de las emociones y la configuración vidas inteligibles en marcos que regulan que cuenta y que no en términos de una economía diferencial de la precarización, «son algunos cuerpos, más que otros, lo que habrán de cargar con la promesa de la felicidad» (Ahmed, 2019, p. 96), el cuerpo resentido de Cristina, queda fuera de los que pueden prometer la felicidad. Para el neoliberalismo, el populismo es un cuerpo enfermo incapaz, ya no de cumplir sus promesas, sino meramente del acto de habla involucrado en prometer. Las gramáticas emocionales del neoliberalismo depositan en ciertos cuerpos, objetos, narraciones, tiempos una emoción. En el discurso del ex-presidente la jerarquía de los sensible niega la salud y la felicidad tanto a Carlotto como a Cristina, cuerpos que no saben/pueden perdonar, cuerpos orientados por el resentimiento. Puede pensarse que en los discursos que llevan las huellas de la hegemonía cultural del neoliberalismo, elaboran una «sistema topológico» (Angenot, 2010), un mapa: distancias, orientaciones, (des)alojos, zonas de proximidad, lejanía o frontera con objetos, cuerpos, relatos, tiempos vinculados a ciertas emociones. La ruta del afecto neoliberal orienta la felicidad lejos del resentimiento es decir del pasado, la memoria, el perdón suspendido, la enfermedad, el malestar, el conflicto social. En otras palabras, "una visión de mundo» (Angenot, 2010) se compone con afectos 
construidos como legítimos, inteligibles y reconocibles que configuran una vida (in)deseable. En este sentido es que lo biográfico tiene tanto peso para el ex-presidente, su vida misma es puesta en juego en sus apuestas discursivas, su secuestro, su experiencia personal es la fuente del imaginario político que sostiene. No es raro que los biografemas (Barthes, 2018) sean otro "fetiche» (Angenot, 2010) del discurso neoliberal.

En el dispositivo de enunciación de Macri, el biografema del secuestro es una tópica recurrente que funciona de mapa interpretativo, como punto de origen de las coordenadas en las que se encuentra, es el centro y brújula de su topología afectiva. En 2018, durante un mensaje grabado de 22 minutos para hablar sobre la crisis económica del país, recurrió a este lugar y momento personal para explicar: «Para mí no es fácil. Quiero que sepan que estos fueron los peores cinco meses de mi vida después de mi secuestro» (3 de Septiembre de 2018). En diciembre de 2019, al terminar su mandato presidencial, estrenó el documental-entrevista «Momentos» (8 de diciembre de 2019). La pieza audiovisual consiste en tres entrevistas con distintos temas. Visualmente es muy sobrio, casi no tiene material de archivo, y gran parte de las escenas consisten en primerísimos primer plano con cámara en mano. El documental consiste en 22 segmentos en este orden con los siguientes títulos: El secuestro, Joven, Antonia, Juliana, Boca, El padre, La muerte del padre, El compromiso, Junio de 2019 (Pre-paso) ¿Por qué creía que los argentinos debían votarlo?, Noviembre de 2019 (Reacción al segmento anterior de junio donde dice por que lo tenían que votar), La herencia, La crisis, La importancia de la democracia, El poder, El aborto, Ricos en expectativas, Venezuela, Alberto Fernández, Sin miedo, Las marchas, El futuro, El despertar. Por su extensión y diversidad temática, el documental amerita un análisis más extenso del que pretende este trabajo. Sin embargo, podemos decir que la lista de segmentos es sumamente elocuente de una cuestión: El secuestro para Macri funciona como su «modelo de llegada» (Sigal y Verón, 2003). De manera análoga al análisis que realizan Verón y Sigal del dispositivo de enunciación peronista, podemos decir hay un mito de origen, un desembarco en la política y en la formación del enunciador. El secuestro es el grado cero del ethos discursivo macrista, el sol de su sistema, todo puede medirse a partir de ese punto de apoyo de donde sus enunciados toman fuerza.

\section{El neoliberalismo como promesa}


A partir de su interpretación de la filosofía derrideana, Levstein y Dahbar consideran que «si el performativo por antonomasia es la promesa, el discurso neoliberal no hace más que incumplirla, es decir acentuar su condición de imposibilidad. Como correlato y doble, la amenaza, aún disfrazada y desmentida o silenciada por el discurso, se cumple hasta excediendo los escenarios más pesimistas» (2020, p. 13). Al recuperar la noción de promesa unida a su par opuesto la amenaza, nos acercamos a entender cual es el funcionamiento de este componente en el discurso neoliberal. Que alguien se presente como un «optimista inclaudicable», supone una promesa de desplazar el momento de ceder, la declinación en un camino, un compromiso con no desistir. La promesa funciona a partir de una estructura narrativa particular que inviste a ciertos objetos de una expectativa. El neoliberalismo como promesa, es una táctica de gobierno de las expectativas, una máquina de producir un futuro. Este tiempo venturoso a parece a asociado a la ideas positivas, alegres, venturosas, como un buen pronóstico. Ante las dificultades, la precarización, la desigualdad ontológica y social, el neoliberalismo propone esperar, la paciencia de la subjetividad emprendedora, mantener la calma en virtud de un futuro prometedor. La esperanza del neoliberalismo es una promesa que hace diferir el malestar emocional. Casi como una profecía de tranquilidad. La promesa es un imperativo a mantener la calma, a suspender el resentimiento. Cuando alguien denuncia o demanda una situación presente de injusticia, se le acusa de resentida, de no creer en la promesa.

En su abordaje del discurso político reciente a partir de distintos lapsus y escenas de enunciación sumamente llamativas, Dahbar y Levstein se proponen «abordar la lengua neoliberal en tanto vehículo, intelectual y afectivo, de un modo de la vida que al tiempo que la hace posible para algunos cuerpos y de unas maneras muy particulares, la vuelve invivible para una inmensa mayoría y por diferentes motivos» (2020, p. 9). La formación discursiva que es objeto de análisis de este trabajo, funciona no solo a nivel ideológico, sino también como expresión de una configuración particular de la sensibilidad, de las emociones legítimas de una época, esto produce modos de subjetivación como modos de vida deseables, a la vez que atenta contra las condiciones de existencia de otras vidas. Cierto dominante de pathos, del discurso social de un momento histórico particular, determina los efectos sobre la sensibilidad a la vez que dota de derecho y fuerza ciertas formas de existencia. Las emociones en el neoliberalismo funcionan de alguna manera a nivel ontológico. Existir puede ser imposible si tu demanda por reconocimiento expresada de manera resentida es ininteligible. Decimos que el enunciado 
de Macri sobre Estela de Carlotto es negacionista, no porque interpreta de manera banal los sucesos y los crímenes de la última dictadura argentina, sino porque arroja las emociones de quienes luchan por el reconocimiento político de la tragedia política al territorio de la impostura, el ridículo, la inadecuación por ser incapaz de poder/saber perdonar.

Por otra parte, estas políticas sobre la legitimidad de la existencia de ciertos actores políticos terminan por homogeneizar una figura de lo deseable. Para Dahbar y Levstein, «el discurso neoliberal produce un desplazamiento constante de lo legal para legitimar al poderoso (unión de fuerza y derecho), acentuando así una tautología entre persona rica e impunidad» (2020, p. 15). Agregamos un tercer término a esa relación de identidad entre rico e impunidad: el «despojo afectivo». La subjetividad neoliberal tiene el núcleo de su deseo y ser en esas tres características. No basta ser impune o rico, hay que estar desprovisto de emociones, el imperativo de mantener la calma. Las pasiones resentidas, esas que para el discurso neoliberal son propias del populismo, enferman el alma.

\section{La autonomía como ideal moral y estigmatización de la demanda}

En la fetichización de los biografemas como una apuesta discursiva que puede explicar el desastre económico de una crisis o compararse con el horror de la violencia autoritarismo de una dictadura, es una operación que descolectiviza las emociones, aquello que tiene magnitud macro-social, dimensiones históricas, tensiones conflictivas, es presentado desde la anécdota priva, el ámbito microsociológico de lo familiar. No es que lo personal sea político, sino que lo político (solo) es personal.

La disminución de lo afectivo al campo de lo individual, se vincula con dos características del discurso neoliberal: la autonomía como ideal moral y la estigmatización de la demanda. Ambas trabajadas por Martínez a partir de un conjunto de imágenes que circularon durante el año 2018, una publicación del Ministerio de Educación donde cuenta la historia de un niño que en condiciones de precariedad extrema expone su vida para ir al colegio y un chiste del comediante Alfredo Casero en una entrevista televisiva. En palabras de la autora, «estos enunciados inauguran también nuevas economías afectivas, en las que el odio y la indiferencia frente a un mundo cada vez más desigual constituyen articulaciones que sedimentan» (Martínez, 2020, p. 46). 
En primer lugar, la autonomía como ideal moral podría resumirse en el imperativo: «quien carece lleva en sí la solución a su propia condición» (Martínez. 2020, p.38). Cuando Macri se refiere al sufrimiento de Estela de Carlotto, le recomienda que perdone, que lo supere; como hizo él que pudo disculpar a sus secuestradores.

A partir de la obra de Butler, Martínez considera «la condición paradójica» de imponer la autonomía como un componente particular del discurso neoliberal que consiste en un imperativo afectivo/subjetivo: «se nos obliga a convertirnos en la clase de sujetos que justamente están excluidos, por las propias condiciones estructurales, del cumplimiento de esa norma» (Butler en Martínez, 2020, p. 39).

Imponer la autonomía como ideal moral en los vínculos entre neoliberalismo y precarización, cuando toma la forma de un apego afectivo, es lo que denuncia la economía feministas en la consigna «amor es trabajo no pago». Cuando se nos pide que hagamos algo por amor, como "ponerse la camiseta de la empresa», esa demanda e imposición sin retribución económica real, más que el valor moral de acercarse al ideal afectivo postulado discursivamente, funciona como un componente central del discurso neoliberal y el ethos emprendedor que configura las subjetividades de este tipo de políticas.

En segundo lugar, otra figura individualizante de los afectos se manifiesta en un «componente típico de esta formación discursiva: la estigmatización de la demanda. Frente a la carencia constatada, los sujetos afectados deben ser capaces de resolver por sí mismos las situaciones, sin apelar a ayuda de ningún tipo» (Martinez, 2020, p. 41). Volviendo a la celebración del resentimiento que plantea Fisher que comentamos anteriormente, hay ciertas emociones que el neoliberalismo necesita reprimir. La enunciación pública de una queja, la visibilización de una situación urgente o una demanda ética por la vida vulnerada, son actos discursivos que movilizan afectos que la política cultural de las emociones del neoliberalismo se propone estigmatizar. Surgen así figuras de la otredad negativa: vagos, ñoquis, planeros, "se embarazan por un plan», «nadie quiere trabajar». La doxa neoliberal responde a la demanda de cuidado común, con el estigma de la demanda, esperando que el problema la resuelva individualmente quien lo experimenta.

\section{Consideraciones finales: Alodoxia afectiva}


En «La promesa de la felicidad», Ahmed recupera "La distinción» de Pierre Bourdieu para explicar cómo se forma la orientación corporal y el gusto o preferencia por ciertos objetos, es un rasgo adquirido a lo largo del tiempo y no producto del azar. El discernimiento del deleite, el disgusto, lo elevado y lo bajo es resultante de un proceso pedagógico que no es ni natural, ni neutral en el que se adquieren tendencias y hábitos, formas de diferenciar el valor afectivo y moral de los objetos. La felicidad no es un resultado de un encuentro azaroso o fortuito, que simplemente sucede, más bien es el efecto de una organización jerárquica.

En palabras de Ahmed:

Cuando una persona dice '¿cómo puede gustarte eso?' formula su juicio contra otro como un rechazo a aceptar que a ella pudiera llegar a gustarle lo que le gusta al otro, y dando a entender que ese objeto en el que inviste su felicidad no es merecedor de ello. Esta diferenciación afectiva es la base de una economía esencialmente moral en la que... las distinciones de mérito constituyen también distinciones sociales de valor (Ahmed, 2019, pp. 79-80).

Consideramos, que esta articulación de Ahmed con Bourdieu puede seguir desarrollándose. Es en este sentido que nos interesa aquí proponer la noción de alodoxia afectiva, como una categoría para interpretar el funcionamiento de ciertos discursos en el contexto de la política cultural de las emociones.

En «La distinción», Bourdieu (1998) presenta el término alodoxia cultural, como un efecto que se manifiesta como un malentendido, una inadecuación, un reconocimiento o una identificación incorrecta. Esta noción indica algo similar a un engaño, «esta veneración indiferenciada, que mezcla la avidez con la ansiedad, conduce a tomar la opereta por la "buena música", la divulgación por la ciencia, la imitación por lo auténtico» (p. 326). A partir de esa «falsa identificación, inquieta y demasiado segura al mismo tiempo» se termina por encontrar «el principio de una satisfacción que debe también algo al sentimiento de la distinción» (idem). Así esta se presenta como «error de objeto, equivocación, creencia mal situada» (p. 331). Esto supone el riesgo de caer en "los falsos reconocimientos que favorecen el discurso dominante» (p. 472). Esta situación algo bochornosa, en palabras de Levstein es una «instancia social del gusto o consumo cultural en que el agente no reconoce su ilegitimidad ya que se encuentra, 
sin saberlo, la confusión de consumir algo demodé o degradado para la cultura legítima... con la actitud de quien está frente a un consumo legítimo» (2004, p. 18).

La alodoxia es un «estado de confusión» o «desajuste» (Levstein, 2004) de quien no reconoce las jerarquías y valores de los consumos culturales. Casi como una ilusión, una fantasía o en palabras de Levstein una idiotez, quien cae en la alodoxia opera en una economía cuyas reglas le son desconocidas, aunque no lo sepa. Nuestra propuesta es pensar a Macri no como el idiota que caracteriza Levstein o los burgueses confundidos de Bourdieu, sino más bien como el referí de una alodoxia afectiva. En otras palabras, en el discurso neoliberal funciona una tecnología de la distinción en lo que se refiere a emociones, una máquina que determina qué emociones son legítimas de sentir y expresar. Como ya hemos visto, para Macri, el resentimiento, el odio, la ira de Carlotto y Fernandez de Kirchner, no solamente es una enfermedad social, sino motivo de indignidad social.

Por otra parte, si pensamos los análisis de Butler (2006) sobre la prohibición/forclusión del duelo público de ciertas vidas consideradas menos legítimas de cariño y merecimiento de los afectos desplegados por los enunciados de los rituales de conmemorativos, en Estados Unidos después del atentado de las torres gemelas, como un efecto de la alodoxia afectiva es similar al negacionismo por comparación de Macri cuando se refiere a Carlotto. La categoría interpretativa que estamos tratando de proponer en este escrito, de alodoxia afectiva funciona como ese efecto de discurso que marca una distinción, como un juez de la moral y la economía afectiva: cuales son las situaciones que deben despertar el miedo, la tristeza, la alegría legítima y cuáles no, cuáles son los cuerpos que merecen respeto conmemorativo, cuales son los relatos, las temporalidades los objetos con reconocibilidad social para generar una emoción acorde a un acontecimiento.

Se puede decir, que la alodoxia afectiva funciona como un mecanismo regulador de las jerarquías que componen la economía afectiva de la hegemonía cultural de una época. Las operaciones discursivas que marcan una diferencia y un desplazamiento de las emociones legítimas y reconocibles socialmente como aceptables por una sociedad. Quizás, la alodoxia afectiva como técnica de gobierno de las emociones en la cultura terapéutica del neoliberalismo tenga entre sus síntomas las recetas de auto-ayuda, las filosofías y metafísicas de lo new age, la educación emocional, el mindfulness y otras expresiones de la cultura neo-evangélica en esta forma de gobierno que tiene en la producción de 
subjetividades un elemento clave en la configuración de economías afectivas marcadas por estos elementos.

En el neoliberalismo, la disputa política por el sentido y la organización de las emociones se manifiesta en una alodoxia afectiva caracterizada por tres movimientos: el odio y el resentimiento son emociones naturalmente negativas, degradantes y peligrosas (deshistorizando la conflictividad y complejidad de la circulación de emociones y sus efectos en el campo social); la autonomía como ideal moral y estigmatización de la demanda (Martinez, 2020) en los que las emociones legítimas son aquellas que se experimentan individualmente y sin elaborar una desobediencia en forma de demanda; y las promesas se vuelven amenaza en una afirmación tautológica entre rico, poderoso (Dahbar y Levstein, 2020) y despojado.

\section{Referencias bibliográficas}

Ahmed, S. (2015). La política cultural de las emociones. México: UNAM.

Ahmed, S. (2019). La promesa de la felicidad. Una crítica cultural al imperativo de la alegría. Buenos Aires:

Angenot, M. (1997). Interdiscursividades. De hegemonías y disidencias. Córdoba: Editorial de la UNC.

Angenot, M. (2010). El discurso social. Los límites de lo pensable y lo decible. Buenos Aires: Siglo XXI editores.

Arfuch, L. (2016), "El giro afectivo. Emociones, subjetividad y política". Revista DeSignis, 24. Barthes, R. (2018). Roland Barthes por Roland Barthes. Buenos Aires: Eterna Cadencia editora. Berlant, L. (2020). El optimismo cruel. Ciudad Autónoma de Buenos Aires: Caja Negra. Bourdieu, P. (1998). La distinción. Criterios y bases sociales del gusto. Madrid: Taurus 
Butler, J. (2006). Vida precaria: el poder del duelo y la violencia. Paidós, Buenos Aires.

Butler, J. (1992). Lenguaje, identidad y poder. Ed. Síntesis, España.

Dahbar, V. y Levstein, A. (2020). Precariedad y (auto)inmunidad para una discusión sobre la vida. En Martínez, F. (Ed.). Discurso y precarización: avatares recientes del neoliberalismo en Argentina (9-23).

Córdoba: Nodo Ediciones. Disponible en Repositorio Digital Universitariohttps://rdu.unc.edu.ar/bitstream/handle/11086/17245/Discurso\%20y\%20precarizaci\%c3\% b3n..pdf?sequence $=6 \&$ isAllowed $=y$

Fisher, M. (2018). Los fantasmas de mi vida: escritos sobre depresión, hauntología y futuros perdidos. Ciudad Autónoma de Buenos Aires: Caja Negra. Lejtman, R. (14 de Marzo de 2021). Mauricio Macri, en su libro Primer Tiempo: “La ex presidenta no está bien, no sé si alguna vez lo estuvo". Infobae. Recuperado de https://www.infobae.com/politica/2021/03/14/mauricio-macri-en-su-libro-primer-tiempo-la-expresidenta-no-esta-bien-no-se-si-alguna-vez-lo-estuvo/

Levstein, A. (2004). Hay que ser realmente idiota para o la infancia del antropólogo. Córdoba: Editorial Fuelle del Sol.

Martínez, F. (2020). Figuras discursivas de la precarización neoliberal: un analisis sociosemiótico. En Martínez, F. (Ed.). Discurso y precarización: avatares recientes del neoliberalismo en Argentina (24-47). Córdoba: Nodo Ediciones. Disponible en Repositorio Digital Universitario https://rdu.unc.edu.ar/bitstream/handle/11086/17245/Discurso\%20y\%20precarizaci\%c3\%b3n..pdf?seq uence $=6 \&$ isAllowed $=\mathrm{y}$ 
Mauricio Macri: "Fueron los peores 5 meses de mi vida después de mi secuestro". (3 de Septiembre de 2018) Infobae Recuperado de https://www.infobae.com/politica/2018/09/03/mauricio-macri-fueronlos-peores-5-meses-de-mi-vida-despues-de-mi-secuestro/

Mauricio Macri le contestó a Estela de Carlotto: “Me da mucha pena que no pueda salir del rencor y del odio", (25 de Marzo de 2021). Infobae Recuperado de https://www.infobae.com/politica/2021/03/25/mauricio-macri-le-contesto-a-estela-de-carlotto-me-damucha-pena-que-no-pueda-salir-del-rencor-y-del-odio/

Mauricio Macri. (8 de Diciembre de 2019). "MOMENTOS". Entrevista completa a Mauricio Macri. [Archivo de Video]. Youtube. https://www.youtube.com/watch?v=PbH7ebCm5yM\&ab channel=MauricioMacri

Mauricio Macri. [Mauricio Macri]. (29 de Julio de 2018). [Publicación de Facebook]. Recuperado de https://www.facebook.com/55432788477/posts/10156760905103478/

Molina, G. (22 de Octubre de 2015). Macri cerró la campaña eufórico y pidió un “Cordobazo del desarrollo de Argentina". Clarín. Recuperado de: https://www.clarin.com/politica/macri-euforicocordobazo-desarrollo-argentina_0 rkJeEL-Fvml.html

Sigal, S. y Verón, E. (2003) Perón o muerte. Los fundamentos discursivos del fenómeno peronista. Buenos Aires: Ed. Eudeba. 